Relations industrielles

Industrial Relations

\title{
La morale dans les relations du travail
}

\section{Gaston Cholette}

Volume 3, numéro 2, octobre 1947

URI : https://id.erudit.org/iderudit/1023564ar

DOI : https://doi.org/10.7202/1023564ar

Aller au sommaire du numéro

Éditeur(s)

Département des relations industrielles de l'Université Laval

ISSN

0034-379X (imprimé)

1703-8138 (numérique)

Découvrir la revue

Citer cet article

Cholette, G. (1947). La morale dans les relations du travail. Relations

industrielles / Industrial Relations, 3(2), 19-20. https://doi.org/10.7202/1023564ar

Tous droits réservés @ C Département des relations industrielles de l’Université Laval, 1947
Ce document est protégé par la loi sur le droit d'auteur. L’utilisation des services d'Érudit (y compris la reproduction) est assujettie à sa politique d'utilisation que vous pouvez consulter en ligne.

https://apropos.erudit.org/fr/usagers/politique-dutilisation/ 


\section{LA MORALE DANS LES RELATIONS DU TRAVAIL}

\section{Gaston CHOLETTE}

Les relations du travail, pour quiconque suit de loin leur évolution, apparaissent comme un ensemble de chocs et de luttes sans fin. La réalité n'est certes pas aussi sombre car, malgré les nombreuses difficultés et les développements sensationnels dont est fréquemment saisie l'opinion publique, il y a encore, heureusement et de plus en plus, des cas de fructueuse collaboration et d'entente qui mériteraient d'être signalés. De toute façon, en dépit des efforts tentés par les influences religieuses et moralisatrices au sein des associations syndicales catholiques groupant patrons ou ouvriers, l'on est encore loin de l'idéal de justice et de charité qui devrait régner dans le monde économique, dans la province de Québec.

La législation dans ce domaine, même si elle est inspirée par le souci d'assurer aux associations ouvrières un statut leur garantissant l'existence et l'essentiel de leurs fonctions, de même que la collaboration harmonieuse des parties dans le règlement des difficultés et la négociation de conventions collectives, est loin de donner satisfaction et d'instaurer automatiquement la paix sociale. Plusieurs considèrent même certaines de ses parties comme un obstacle au progrès de la justice, la procédure qu'elles imposent constituant une série de difficultés dont on se plaît, parfois, à compliquer le mécanisme et l'interprétation ou que l'on utilise comme un tampon destiné à impatienter les ouvriers en retardant systématiquement les ententes.

Serait-il préférable d'améliorer cette législation? Sans aucun doute, car en dernière instance, la force de la loi est souvent, presque toujours même, la seule qui puisse faire entendre raison à plusieurs. Toutefois, l'exemple des lois actuelles ne prouve-t-il pas clairement que l'on ne doit pas compter uniquement sur elles, même transformées, pour obtenir des résultats satisfaisants ? Quid leges sine moribus: que valent les lois sans les moeurs ? Les principales « encycliques sociales», notamment Quadragesimo Anno et Divini Redemptoris, sont trop explicites pour que les catholiques gardent encore des doutes à ce sujet.

La moralité, voilà le meilleur correctif aux grands malaises dans les relations industrielles. La moralité, en effet, ne se rapporte pas uniquement aux vertus de tempérance et de chasteté, aux sixième et neuvième commandements, mais à toutes les vertus et à tous les actes humains. Elle n'est donc pas étrangère à la justice et à la charité, les deux grandes vertus sociales. L'on a tort, en certains milieux, de restreindre la signification de ce mot pour ne l'appliquer qu'aux problèmes de la pureté.

Ceci admis, voyons de quelle façon la moralité doit régir les actions et les attitudes de tous ceux qui sont engagés dans les relations du travail. De toutes parts, même dans les milieux qui n'ont pas de sympathie spéciale pour les employeurs, on se plaint aujourd'hui d'une diminution sensible dans la compétence et la conscience professionnelle des ouvriers. Les unions ouvrières, dit-on, ne devraient pas songer uniquement aux augmentations de salaires et aux congés, mais aussi à former des travailleurs habiles et consciencieux, soucieux de respecter leurs engagements et de donner satisfaction à l'employeur. Ce sera souvent pour elles le meilleur moyen d'obtenir justice dans leurs revendications et de se gagner la faveur de l'opinion publique comme des patrons. Ceux-ci ont droit, d'ailleurs, en stricte justice commutative, à un rendement convenable de leurs employés durant tout le temps qu'ils sont à leur service. Ils doivent compter aussi sur le respect de leur propriété et sur la possibilité de maintenir leurs entreprises. La société, surtout, a droit à la sauvegarde du bien commun, lequel est gravement menacé lorsque certaines greves de grande envergure aflectant la production ou la distribution de services ou de biens indispensables, sont déclenchées sans motifs suffisants.

Les employeurs, d'autre part, n'auraient pas raison de se refuser à toute amélioration du sort de leurs employés, sous prétexte qu'en retour ces derniers ne donneront pas encore tout leur rendement et ne seront jamais satisfaits. L'on doit admettre que, dans bien des cas, lorsqu'un ouvrier ne travaille pas avec ardeur, c'est parce que l'employeur n'a pas réussi à l'intéresser au succès do l'entreprise. Certains employeurs, réfractaires à la doctrine sociale chrétienne, ont recours à toutes sortes de moyens, légaux et autres, dans le but de nuire à l'organisation syndicale. Très souvent, dans la plupart des cas même, ils sont les principaux responsables des grèves dont on tente injustement de faire rejaillir tout l'odieux sur l'ouvrier. Ils retardent par là les progrès d'un syndicalisme sain et préparent indirectement les voies au communisme tant dénoncé, du moins aux unions internationales. 
C'est surtout au cours des négociations de conventions collectives et du règlement des griefs que la moralité doit être à l'honneur, chez les employeurs comme chez les employés. Si les deux parties, dans ces circonstances, étaient toujours de bonne foi, animées du seul désir de satisfaire aux exigences de la justice et de la charité, combien de temps serait épargné, combien de rancoeurs évitées.

Ceci nous amène à traiter de la moralité des hommes de loi, lesquels jouent un si grand rôle dans les relations du travail. Leur fonction consiste à interpréter et à faire respecter la loi, dans sa lettre mais surtout dans son esprit. Ils seraient donc blâmables si leur véritable travail, dans ce domaine, se limitait à se ranger du côté du plus fort, sans égard pour la morale et la doctrine sociale de l'Eglise. La loi ne doit pas être considérée, même par eux, comme un ensemble de moyens de protéger les intérêts d'une partie aux dépens des règles supérieures de la justice. Ils ont pour mission de faire procéder les deux parties dans l'ordre, non de se plaire dans les manoeuvres de contournement ou d'interprétation restrictive de la loi. Il va sans dire qu'il serait tout à faif immoral de s'ingénier à entretenir et à envenimer les conflits sans égard à la justice et à la paix sociale, en multipliant les chinoiseries légales dans le seul but d'en retirer un plus grand profit personnel.

Quant à l'Etat, investi de l'autorité et principal responsable du bien commun, il a pour tâche, dans le domaine des relations du travail, de faciliter l'avènement d'un ordre chrétien. Dans son action exécutive, autant que législative, il doit donc s'inspirer avant tout des exigences de la justice et de la charité, non d'un légalisme désuet et restrictif. Tout en essayant d'empêcher les relations industrielles de tourner au pire et de constituer un sérieux danger pour le bien commun de la société, il doit adopter une politique progressive et faire la différence entre les tendances étrangères visant au désordre et l'action des associations saines travaillant à l'instauration de la justice. En arbitre impartial, il ne doit pas généraliser les accusations de communisme et les porter contre une seule des parties en cause, encore moins couvrir de ce terme d'opprobe les légitimes efforts de la classe ouvrière vers une meilleure organisation syndicale ei le respect de ses droits.

\section{QU'EST-CE QU'UNE ORGANISATION REPRÉSENTATIVE ?}

Jean-Pierre DESPRES

En principe, la liberté syndicale implique pour le travailleur la faculté d'adhérer à une organisation de son choix ou de n'adhérer à aucune organisation. Cependant, dans des cas particuliers, l'exercice efficace du droit d'association de la majorité des travailleurs dans une entreprise déterminée peut justifier l'application de certaines clauses dites de sécurité syndicale. Bien qu'en pratique la multiplicité des organisations syndicales puisse présenter des inconvénients pour la solidarité ouvrière, il reste que le respect du principe de la liberté syndicale implique également le pluralisme syndical sur le plan de l'entreprise, sur le plan de l'industrie et sur le plan national. Actuellement le problème du pluralisme syndical ne se pose pas dans tous les pays, mais il présente un intérêt immédiat en France, aux Etats-Unis et au Canada.

Dans ces trois pays existent plusieurs mouvements syndicaux qui préconisent une conception particulière de l'ordre politique, économique et social. De tous les côtés, des militants syndicalistes ont déploré à plusieurs reprises cette division au sein de la classe ouvrière. Le pluralisme syndical, fait-on observer, est source de rivalités préjudiciables aux travailleurs dont le patronat sait tirer profit, bien que la législation le lui interdise formellement; source de complication et de confusion aussi pour les fonctionnaires ou les patrons qui cherchent une représentation ouvrière. Ces observations sont fondées, mais il faut reconnaître que le pluralisme découle logiquement du principe de la liberté syndicale.

Les tentatives d'unification syndicale, qui n'ont abouti qu'à une impasse tant en France, qu'aux Etats-Unis et au Canada, démontrent clairement que le pluralisme syndical est inscrit dans les faits. Il semble que c'est vers l'unité de représentation auprès des pouvoirs publics ou des entreprises que réside la solution à ce problème, et non vers l'unification syndicale pure et simple. Que l'unité de représentation conduise éventuellement à l'unité syndicale, la chose est possible et même désirable. Mais c'est là un objectif éloigné et non une nécessité immédiate. Cependant, tant qu'existe le pluralisme synảical, la représentation 